\title{
Carcinoma in situ of the male breast
}

\author{
F. M. COLE AND A. H. QIZILBASH \\ From the Departments of Pathology, McMaster University Medical Centre and Henderson General \\ Hospital, Hamilton, Ontario, Canada
}

SUMmARY Two cases of carcinoma in situ of the male breast are described: in one patient it arose as a complication of gynecomastia; in the other, it occurred 'de novo' and proceeded to infiltration with widespread metastases. We reviewed 233 cases diagnosed clinically and histopathologically as gynecomastia to see if we could discover other instances of malignant transformation but none was found. Thirty-two cases of infiltrating male breast cancer were also examined. In 11 there was associated intraduct change. In only one of the 32 cases was there evidence of associated microscopic gynecomastia.

Carcinoma in situ occurring in the ductal epithelium of the female breast is a well recognised entity (Carter and Smith, 1977). The analogous lesion in the male breast, however, is rarely recorded. We describe two patients with this condition. One patient presented with a breast mass which proved to be carcinoma in situ. This was excised, but an infiltrating carcinoma later developed at or near the site of the original excision. The second patient presented with classical gynecomastia. Histologically this showed gynecomastia with focal areas of in situ malignancy superimposed.

As a result of these findings we evaluated 32 cases of infiltrating cancer of the male breast in an attempt to determine how frequently, if ever, the in situ ductal change coexisted with an infiltrating lesion, and we also examined 233 cases of gynecomastia to find out if other patients showed a similar transition from benign epithelial hyperplasia to carcinoma in situ.

\section{Case reports}

CASE 1

A 64-year-old man presented in June 1968 with a slightly bloodstained discharge from the right nipple which had been present for about one week. He also complained of a small, firm, painless mass, about $1 \mathrm{~cm}$ in diameter, which was situated $1 \mathrm{~cm}$ medial to the nipple. This had been present for about six months. His past health had been good apart from long-standing chronic bronchitis and emphysema. A general physical examination revealed

Received for publication 30 April 1979 no abnormality apart from the breast lesion which was excised through a subareolar incision.

\section{Pathological findings}

The specimen consisted of a portion of fibrofatty tissue measuring $3 \times 2 \times 1 \mathrm{~cm}$, in which there was an ill-defined mass, $1 \times 1 \times 1 \mathrm{~cm}$. On section dilated ducts could be identified, and gentle pressure resulted in soft, grey-white material exuding from the ducts. Microscopically the dilated ducts were filled with epithelium and comedones (Fig. 1). The epithelium was many layers thick and thrown into papillary projections which in places completely filled the duct lumen. Calcification was present within the amorphous comedones, within the epithelium, and in the adjacent stroma. The epithelial cells showed marked atypia with variations in nuclear size, shape, and staining properties (Fig. 2). Mitotic figures were frequent -3 or 4 per high-power field. Many were atypical in form. The stroma was dense and acellular with no periductular loose fibrous tissue. Serial histological sections were prepared ( 5 microns thick) through the entire mass, and one in every 20 was stained and examined. At no point was there any evidence of infiltration. The findings were interpreted as showing intraduct carcinoma in situ with no evidence of previous gynecomastia or infiltration.

\section{Subsequent course}

The patient was seen again in 1972 with another mass situated beneath the previous surgical incision. There was no clinical evidence of axillary lymph node or distant metastases. The mass measured $2 \times 1 \times$ $1 \mathrm{~cm}$ and was hard and ill-defined. Microscopically 


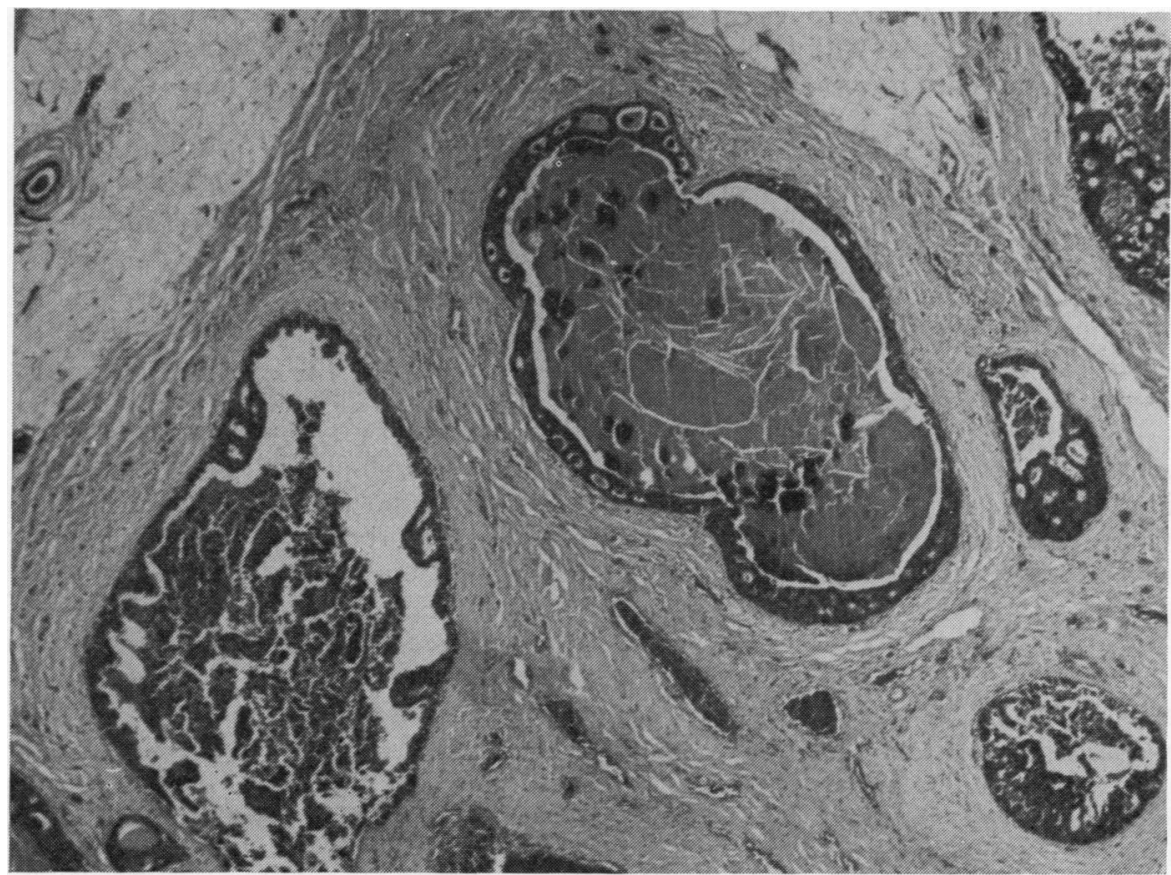

Fig. 1 Dilated ducts filled with comedones and papillary epithelium. Haematoxylin and eosin $\times 40$

$8 \overrightarrow{0}$ ํํ

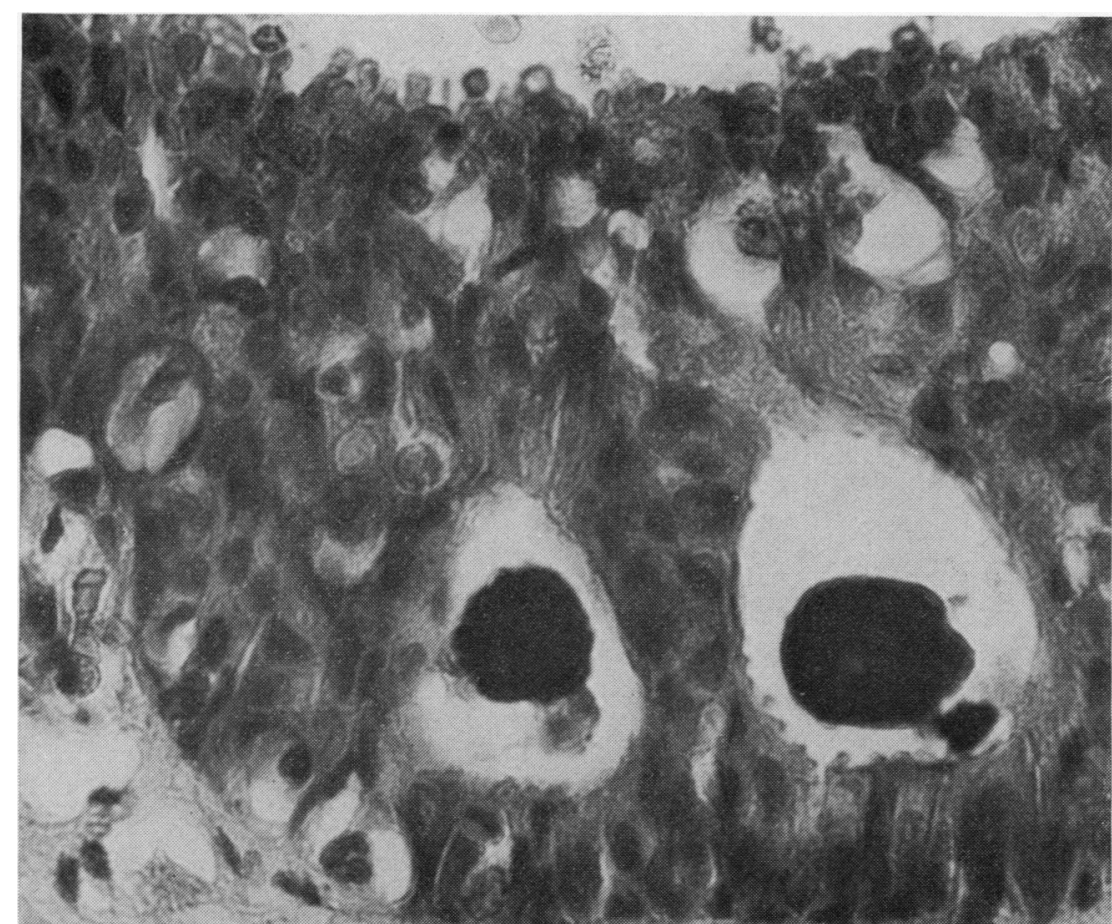

Fig. 2 High-power detail of the epithelium which is many layers thick with marked cytological atypia and calcifications. $H$ and

$E \times 500$ 
there was an extensive infiltrating duct carcinoma which was provoking a brisk fibrous tissue stromal response (Fig. 3). There was no evidence of residual intraduct change. Five lymph nodes showed nonspecific, reactive hyperplasia only with no sign of metastases. A further local recurrence occurred in 1972 and 1974, and again it was removed together with nine lymph nodes, all of which contained metastases. In 1975 the patient had a pathological fracture of the left hip. This was treated by pinning and plating. Tissue removed from the fracture site contained metastatic tumour of similar appearance to the breast tumour. A radiological survey demonstrated metastatic lesions in the sternum and two ribs. A bilateral orchidectomy was carried out. He was seen in the follow-up clinic until 1976 during which time his response to therapy was good, but he was then lost to follow-up.

\section{CASE 2}

A 32-year-old man was admitted with a mass in the right breast which had been present for about six months. There was no discharge or pain. His general health was excellent and he was receiving no medication. His previous medical history was noncontributory. The mass was situated immediately beneath the nipple and measured $3 \times 2 \mathrm{~cm}$. It was firm and movable with no attachment to muscle. There was some tenderness to palpation but no pain.
The other breast was normal. A general physical examination revealed no abnormality. The mass was ramoved and the left nipple was left intact.

\section{Pathological findings}

The specimen consisted of a firm, rubbery disc or tumour, $3 \mathrm{~cm}$ in diameter and $2 \mathrm{~cm}$ thick. It was cut into $3 \mathrm{~mm}$ slices and blocked. Microscopically the changes were predominantly gynecomastia (Fig. 4). The stroma in the periductal areas was hyperplastic and loosely arranged, and the ducts showed elongation and branching. There was very marked epithelial proliferation, together with areas in which the ducts were almost completely obliterated. There was loss of nuclear polarity and marked pleomorphism and hyperchromatism (Fig. 5). Mitotic figures, both normal and abnormal, were plentiful ( 5 to 6 per high-power field), and occasional foci of calcification were seen. These appearances were interpreted as representing in situ carcinomatous change. Serial histological sections were cut and one in $\mathbf{2 0}$ was stained and examined. No infiltration was evident. The pathological diagnosis was gynecomastia of the florid type with superimposed areas of intraduct carcinoma. All residual breast tissue was then excised together with five axillary lymph nodes. Examination of the remainder of the breast tissue showed changes similar to that seen in the original material. There were no metastases in

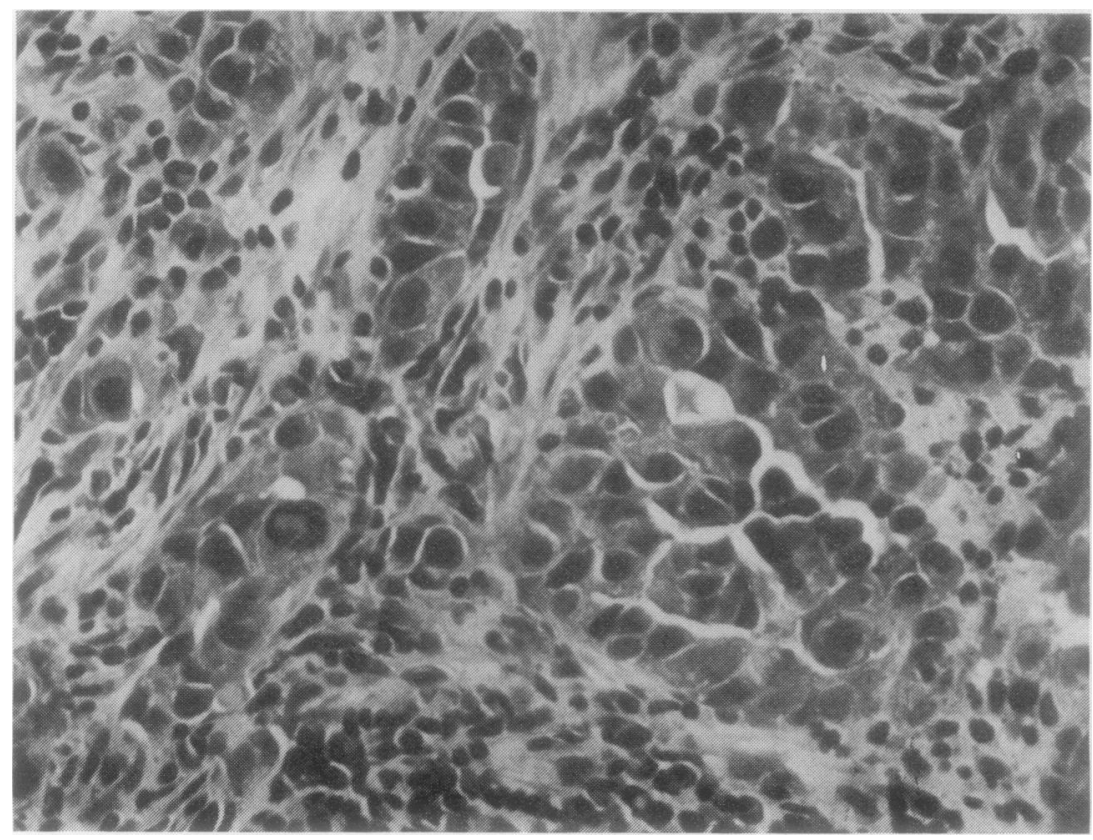

Fig. 3 Details of infiltrating duct carcinoma. $H$ and $E \times 125$ 


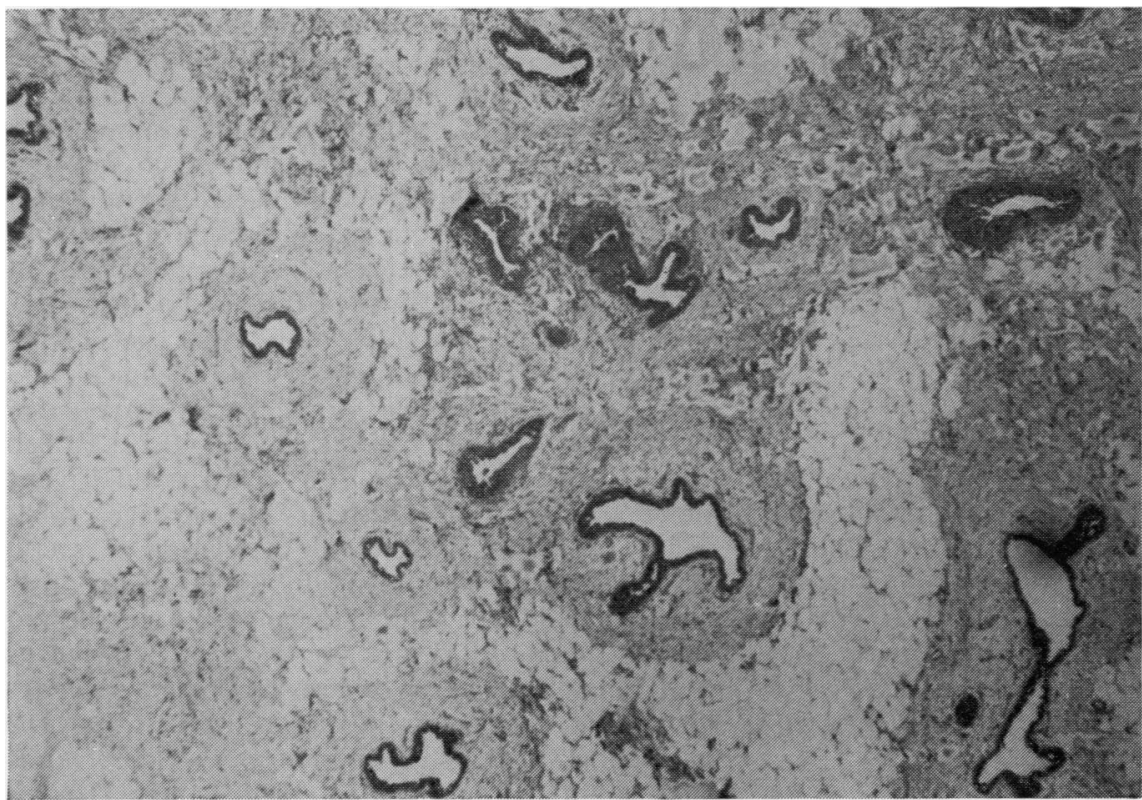

Fig. 4 Low-power view showing changes of gynecomastia. $\mathrm{H}$ and $E \times 30$

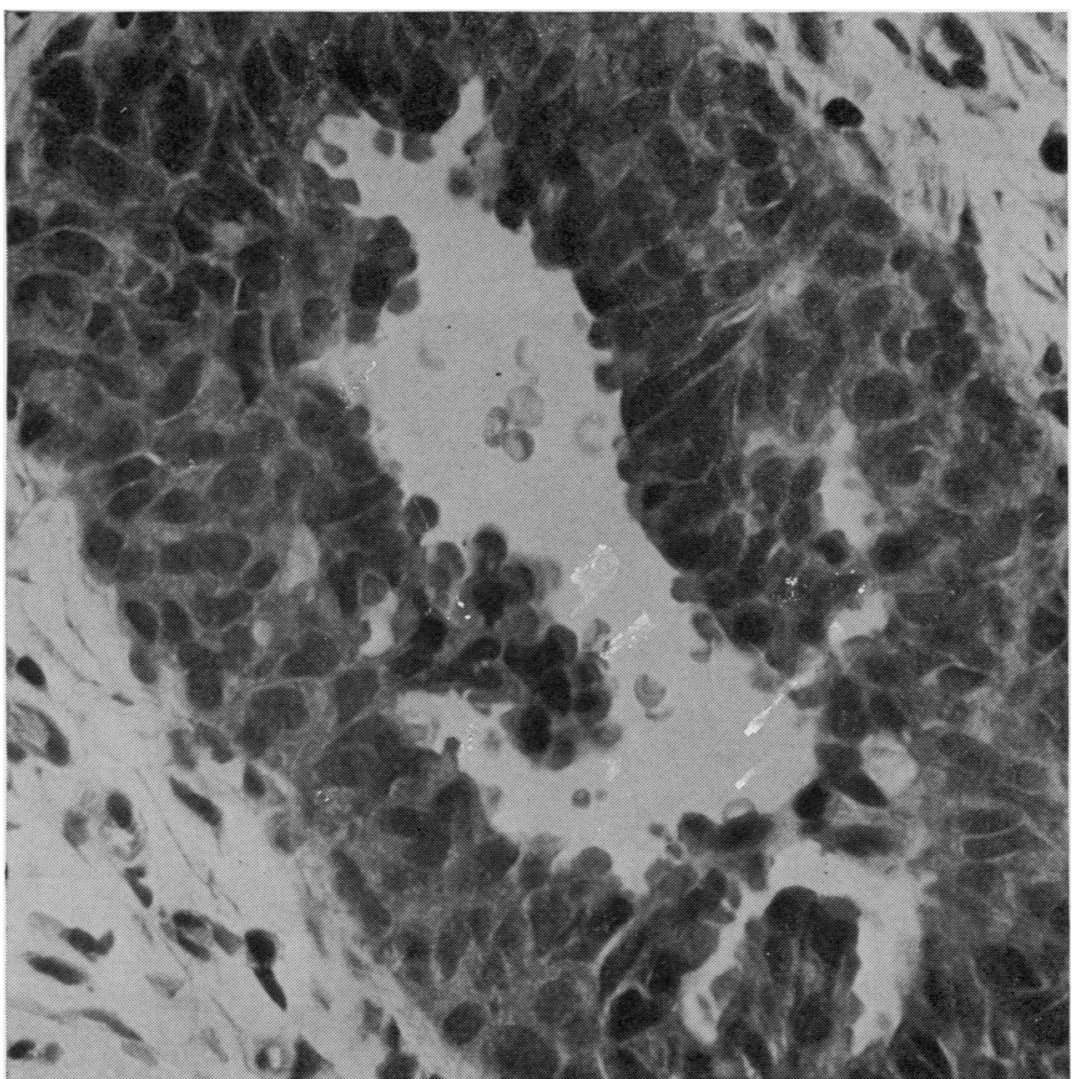

Fig. 5 High-power view showing almost complete obliteration of the duct, loss of nuclear polarity, and marked nuclear atypicality. $H$ and $E \times 300$ 
the lymph nodes. He was seen one year after surgery and at that time had no signs or symptoms of recurrence.

\section{Review of 233 cases of gynecomastia and 32 cases of infiltrating cancer}

Two hundred and thirty-three cases of gynecomastia on file were reviewed. The histological criteria of Williams (1963) were used, and all cases fell into one of two types described by her.

\section{TYPE 1}

The florid type is characterised by increased numbers of ducts, in some cases showing pseudolobular formation. The ducts have irregular lumens, and the epithelium consists of three or more layers with small papillae. Around the ducts there are cuffs of loose connective tissue, and these are well demarcated from the stroma, which is increased in volume and consists of dense collagen tissue with varying fibroblastic proliferation.

TYPE 2

The quiescent type is characterised by slightly increased numbers of ducts with irregular lumens and often slight ectasia. Little or no proliferation of the epithelium is present. There is no loose connective tissue around the ducts, and the stroma extends as far as the basement membrane of the ducts. The stroma is increased in volume without pronounced fibroblastic activity and often with hyalinisation.

The cases of the florid type often show brisk epithelial proliferative changes, but in no case did these changes even approach the degree of cytological abnormality and mitotic activity, both normal and abnormal, that were seen in the present case 2 . In no case was there evidence of the calcific foci.

Thirty-two cases of infiltrating breast cancer were reviewed. Detailed accounts of both clinical and pathological features of large series have been described by other authors (Crichlow, 1972; Holleb et al., 1968; Liechty et al., 1967; Norris and Taylor, 1969; Scheike, 1975; Visfeldt and Scheike, 1963) and will be discussed here only in relation to several relevant findings. Of the 32 tumours, 23 were poorly differentiated infiltrating duct cancers. Four showed clear glandular differentiation, two were classified as encephaloid cancers, two were predominantly papillary, and one was mucinous. Eleven of the infiltrating lesions showed a clearly defined intraduct component (Fig. 6). In eight of these 11 cases the intraduct lesions were of the comedo type, and all showing this type of change also showed focal calcification occurring either within the epithelium or in the comedones. In one of the 32 tumours the adjacent breast tissue showed gynecomastia also.

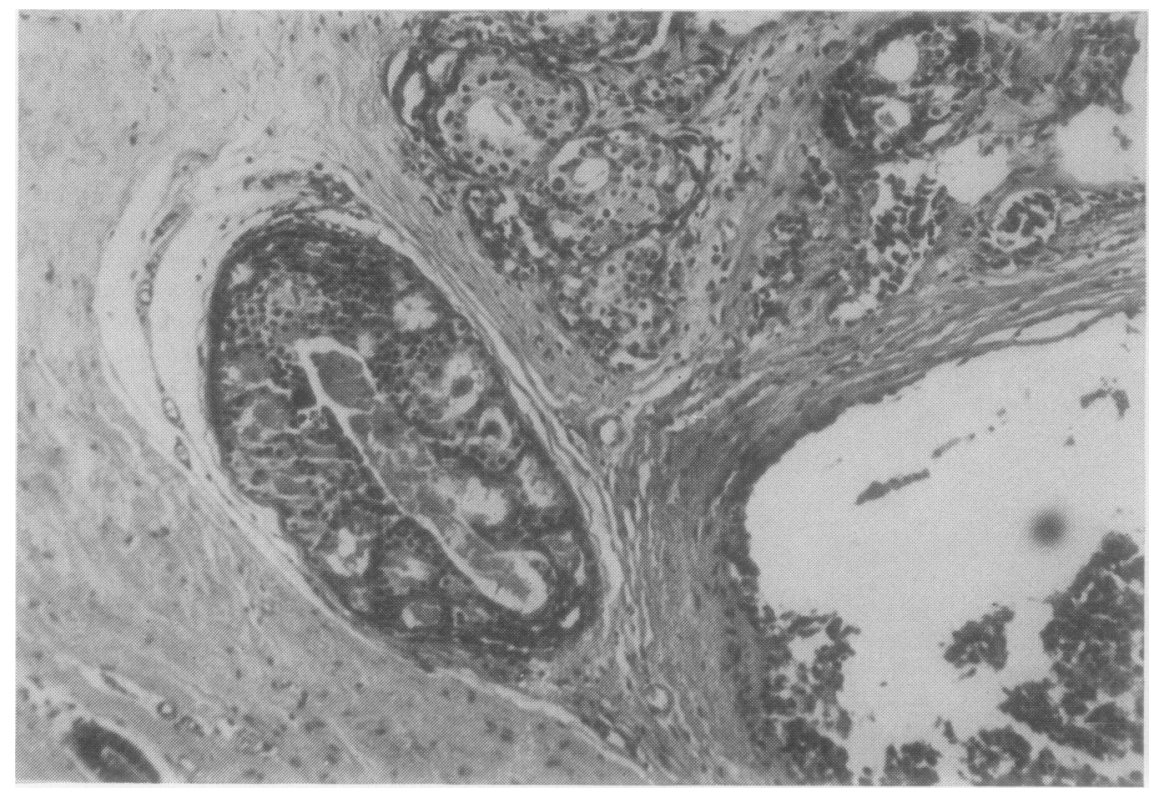

Fig. 6 Intraduct carcinoma with adjacent infiltrating cancer. $H$ and $E \times 80$ 


\section{Discussion}

Carcinoma in situ is a rare lesion whether arising 'de novo' in the male breast ducts, as in case 1 , or in association with gynecomastia, as in case 2 . Little mention is made in the literature regarding the 'de novo' in situ lesion. In many large comprehensive studies dealing with male mammary cancer (Crichlow, 1972; Holleb et al., 1968; Liechty et al., 1967; Norris and Taylor, 1969; Scheike, 1975; Visfeldt and Scheike, 1963) intraduct cancer without an infiltrating lesion is either not mentioned or it is specifically stated that it was not seen. One study (McDivitt et al., 1968) makes passing mention of the in situ lesion, stating that it is entirely similar histologically to that seen in the female breast but no further details are given. In our study of 32 cases of infiltrating duct cancer, there were 11 cases in which there was accompanying intraduct cancer in the ducts of the adjacent breast tissue. This might be regarded as evidence supporting the origin of infiltrating lesions from a preceding intraduct carcinoma. If infiltration is preceded by intraduct change then the infrequency with which it is seen might reflect a very short phase which occurs before infiltration takes place. It is of some interest to note that, of the 11 cases in which intraduct change was seen in association with infiltration, in eight cases it was of the comedo type and in all eight cases there was microscopic calcification. This feature was also seen in cases 1 and 2 but not in the cases comprising the series of gynecomastia.

There is some epidemiological and histopathological evidence of a relationship between gynecomastia and cancer but there is almost unanimous agreement that this association is probably rare. Patients with conditions in which clinical gynecomastia is a feature appear to suffer a higher incidence of breast cancer. Bilharzia damages the liver and causes hyperoestrogenism with gynecomastia in men. The disease is common in Egypt, and it is claimed that male breast cancer constitutes about $5 \%$ of all breast malignancies, a far higher incidence than is encountered in other countries (El Gazayerli and Abdel-Aziz, 1963).

Among 21 cases of male breast cancer, Jackson et al. (1965) found three patients with Klinefelter's syndrome and considered there may be a relationship between this syndrome in which gynecomastia is a feature and mammary cancer. They claimed that this represents a vastly increased incidence when compared with non Klinefelter males. Gynecomastia and breast cancer have also followed administration of oestrogens for prostatic cancer (Abramson and Warshawsky, 1948; Howard and Grosjean, 1948; O'Grady and McDivitt, 1969) but, considering the extensive use of oestrogens for this condition, this complication rate must be regarded as almost negligible.

Microscopic gynecomastia occasionally shows florid and sometimes worrisome epithelial hyperplasia but only occasionally has definite malignant change been documented. Authors who have studied large numbers of cases (Karsner, 1946; Lyall, 1947; Wheeler et al., 1954; Sirtori and Veronesi, 1957; Williams, 1963; Haagensen, 1971) have encountered this change only once or at the most on two occasions. Nevertheless, McDivitt et al. (1968) mention a small group in which the epithelial atypicality is so marked that a firm differentiation between hyperplasia and in situ cancer cannot be made. In the present study, case 2 showed these abnormalities to a degree far in excess of the other 233 cases reviewed. The infrequency of this coexistence is also supported by our own observations that, of the 32 cases of infiltrating cancer, in only one instance was there associated histological gynecomastia.

We thank the many pathologists who allowed us to examine the pathological material. We also thank Mrs Jackie Rowan who typed the manuscript.

\section{References}

Abramson, W., and Warshawsky, H. (1948). Cancer of the breast in the male, secondary to estrogenic administration. Journal of Urology, 59, 76-82.

Carter, D., and Smith, R. R. L. (1977). Carcinoma in situ of the breast. Cancer, 40, 1189-1193.

Crichlow, R. W. (1972). Carcinoma of the male breast. Surgery, Gynecology and Obstetrics, 134, 1011-1019.

El Gazayerli, M. M., and Abdel-Aziz, A. S. (1963). On bilharziasis and male breast cancer in Egypt. British Journal of Cancer, 17, 566-571.

Haagensen, C. D. (1971). In Diseases of the Breast, 2nd edition, pp. 76-85. Saunders, Philadelphia and London.

Holleb, A. I., Freeman, H. P., and Farrow, J. H. (1968). Cancer of the male breast. Part 2. New York State Journal of Medicine, 68, 656-663.

Howard, R. R., and Grosjean, W. A. (1948). Bilateral mammary cancer in a male coincident with prolonged stilbestrol therapy. Surgery, 25, 300-303.

Jackson, A. W., Muldal, S., Ockey, C. H., and O'Connor, P. J. (1965). Carcinoma of male breast in association with Klinefelter syndrome. British Medical Journal, 1, 223-225.

Karsner, H. T. (1946). Gynecomastia. American Journal of Pathology, 22, 235-315.

Liechty, R. D., Davis, J., and Gleysteen, J. (1967). Cancer of the male breast: forty cases. Cancer, 20, 1617-1624.

Lyall, A. (1947). Chorioncarcinoma of the testis with gynaecomastia: report of a case with early breast cancer. British Journal of Surgery, 34, 278-280. 
McDivitt, R. W., Stewart, F. W., and Berg, J. W. (1968). Tumors of the Breast (Atlas of Tumor Pathology, Second Series, fasc. 2), pp. 106-109. Armed Forces Institute of Pathology, Washington, DC.

Norris, H. J., and Taylor, H. B. (1969). Carcinoma of the male breast. Cancer, 23, 1428-1435.

O'Grady, W. P., and McDivitt, R. W. (1969). Beast cancer in a man treated with diethylstilbestrol. Archives of Pathology, 88, 162-165.

Scheike, O. (1975). Male breast cancer. Acta Pathologica et Microbiologica Scandinavica, Supplement, 251, 3-35.

Sirtori, C., and Veronesi, U. (1957). Gynecomastia. Cancer, 10, 645-654.
Visfeldt, J., and Scheike, O. (1963). Male breast cancer. Cancer, 32, 985-990.

Wheeler, C. E., Cawley, E. P., Gray, H. T., and Curtis, A. C. (1954). Gynecomastia. Annals of Internal Medicine, 40, 985-1004.

Williams, M. J. (1963). Gynecomastia. American Journal of Medicine, 34, 103-112.

Requests for reprints to: Dr F. M. Cole, Section of Laboratory Medicine, McMaster University Medical Centre, 1200 Main Street West, Hamilton, Ontario, L8S 4J9, Canada. 